\title{
Magnetic signatures of subsurface faults on the northern upper flank of Mt. Etna (Italy)
}

\author{
Rosalba Napoli*, Gilda Currenti and Antonino Sicali \\ Istituto Nazionale di Geofisica e Vulcanologia, Sezione di Catania, Osservatorio Etneo, Italy \\ Article history: received September 24, 2020; accepted November 27, 2020
}

\begin{abstract}
A ground magnetic study was performed on the northern upper flank of Mt. Etna to provide new insights into subsurface volcano-tectonic structures. The high resolution magnetic survey was focused on the main structures of Piano delle Concazze, a large flat area dominated by the NorthEast crater and bounded by the rim of the Valle del Leone depression and the extremity of the NorthEast Rift. More than 2,500 measurements were gathered with a sampling step of about $3 \mathrm{~m}$ covering an area of about $0.2 \mathrm{~km}^{2}$. The total-intensity anomaly field shows the presence of intense SouthNorth aligned maxima related to shallow geological structures affecting this area. Filtering techniques and 2.5D modeling have been applied for the determination of the magnetic source parameters. In order to distinguish the near surface structure, filters of the vertical derivatives, Butterworth high-pass and the tilt derivative were used. The 3D Euler deconvolution has been applied to estimate the depth and the structural indices of the causative sources. The calculated structural indices, that express the geometrical nature of the source, are in agreement with forward modeling. They show that the area is mainly affected by subvertical normal fault and the estimated depth of magnetic sources ranges between $10 \mathrm{~m}$ and $40 \mathrm{~m}$.

Our total field magnetic survey shows that characteristic magnetic anomalies are related to fault zones in the Piano delle Concazze that are well consistent with the local tectonics. The subsurface structures that have been detected allowed to delineate the general structural framework of the area. In particular, it was possible to clarify that these structures seem to be not deep rooted and consequently they can hardly act as preferential pathways for magma ascent.
\end{abstract}

Keywords: Magnetic survey; Mt. Etna; Filtering technique; 2.5D modelling; 3D Euler deconvolution.

\section{Introduction}

The dynamics of active volcanoes, is closely related to local and regional structures (faults, rift, intrusions) that are not often exposed. Indeed, magma accumulation and migration which can lead to different volcanic eruptions are strongly controlled by the main volcano-tectonic structures. Therefore, mapping and investigation of their spatial distribution and their characteristics (geometry, depth, etc.) are critical to better understand volcano-tectonic activity and for volcanic hazard assessment [Lopez-Loera et al., 2010]. In volcanic environment, even if the main structures are recorded in the general geological maps, their exact course is often debatable because their field evidence is obscured by lava flows, pyroclastic rocks and ash produced by 


\section{Rosalba Napoli et al.}

the more recent eruptive activity and by strong erosion. In these cases, geophysical surveys can give additional evidences [Barberi et al., 2004; Schrott and Sass, 2008; Blaikie et al., 2014], and among them, the magnetic investigation has been widely and efficaciously used in detecting concealed and subsurface volcano-tectonic structures. The interpretation of magnetization contrasts, appropriately integrated with the available geophysical and geological knowledge of the investigated area, has provided valid information on the relationships between the various volcanic and/or tectonic structures both at local and regional level worldwide [Finn and Morgan, 2002; Blanco-Montenegro et al., 2003; Napoli et al., 2007; Napoli and Currenti, 2016; Caratori Tontini, 2016; Demirel et al., 2020; Yan et al., 2018]. In volcanic areas, indeed, the strong magnetization contrasts generated by the presence of rocks with different magnetic properties (susceptibility, induced and remanent magnetization) make this method and the related anomaly maps an efficient tool to identify, delineate, and estimate the depth of the subsurface complex structures. In this context, of particular interest is the detection of faults, that are usually associated with subtle linear magnetic anomalies that may arise from contrasts caused by tectonic juxtaposition of layers with different magnetic properties [Dobrin, 1960; Grauch et al., 2000; Hudson et al., 2001].

In this paper a total magnetic field survey was carried out to investigate the main structures in Piano delle Concazze (PDC) a large flat area on the northern upper flank of Mt. Etna volcano (Figure 1). During the last centuries, PDC has been affected by several eruptive events triggered by magmatic intrusion fed by the central conduit [Branca and Del Carlo, 2005]. Generally, lava flows emitted here are characterized by a high effusion rate and have seriously threatened, and sometimes destroyed the near inhabited areas as happened during the 2002 eruption [Andronico and Lodato, 2005]. Flank eruptions, therefore, represent a high hazard, for this flank of Mt. Etna and in particular for PDC, that, despite being deserted, is among the most popular tourist destination and is usually frequented by researchers, which taking advantage of the Pizzi Deneri Observatory facility, nearby located, carry out monitoring activity and advance research experiments throughout the year. In this area, the main structural features of the northern flank intersect each other producing a complex dissected geological framework where particular attention should be paid to the fault systems, that can be activated by magma intrusions. The high resolution ground magnetic survey, carried out in the autumn of 2018, was aimed to identify and separate by discrete Fourier-transform algorithms the shallow and deep-seated faults, affecting this area. 3D Euler deconvolution and 2.5D modeling, were also applied to estimate their depths and to better define their geometry and spatial distribution and consequently to elucidate the relationships between them.

\section{Geological background}

PDC is a flat area in the northern upper flank of Mt. Etna volcano (Figure 1), dominated by the North-East crater and bounded by the rim of the horse-shoe-shaped depression of the Valle del Leone (VDL) and the upper extremity of the North-East Rift zone. The VDL, located about $600 \mathrm{~m}$ above the basal plane of the wider depression of the Valle del Bove (VDB), was formed by a progressive collapse after the larger flank failure, that produced the VDB [Azzaro et al., 2012]. Its rim overlaps the remains of the summit caldera of the Ellittico volcano, a large central volcanic edifice that marked the NW displacement of the Mt. Etna uppermost feeding system from the previous small volcanoes located under the area now occupied by the VDB [Calvari et al., 2004], and whose caldera was generated about $15 \mathrm{ka}$ ago by a series of plinian eruptions [Coltelli et al., 2000].

The North-East Rift is a $5 \mathrm{~km}$ long and $1 \mathrm{~km}$ wide topographic ridge made up of lavas and pyroclastics [Monaco et al., 2010]. It represents a fractured area, extending along a NE direction from the summit area up to $1500 \mathrm{~m}$ a.s.l., where magma, favored by structural weakness and local tectonic stress, often intrudes [Andronico and Lodato, 2005]. During the last two centuries, indeed, the Rift has been particularly active and has been affected by several eruptive events (e.g. 1911, 1923,1947, 1981, 2002-2003, 2008) triggered by lateral magmatic intrusion, which produced the opening of long eruptive fissures [Branca and Del Carlo, 2005; Monaco et al., 2010] with emission of lava flows, characterized by a high effusion rate, that reached the lowest altitudes [Andronico and Lodato, 2005].

The PDC area is characterized by the presence of volcanic products related to the activities of the Ellittico volcano [Coltelli et al., 1994] that are partially buried by lava flows and volcaniclastic deposits produced by the 

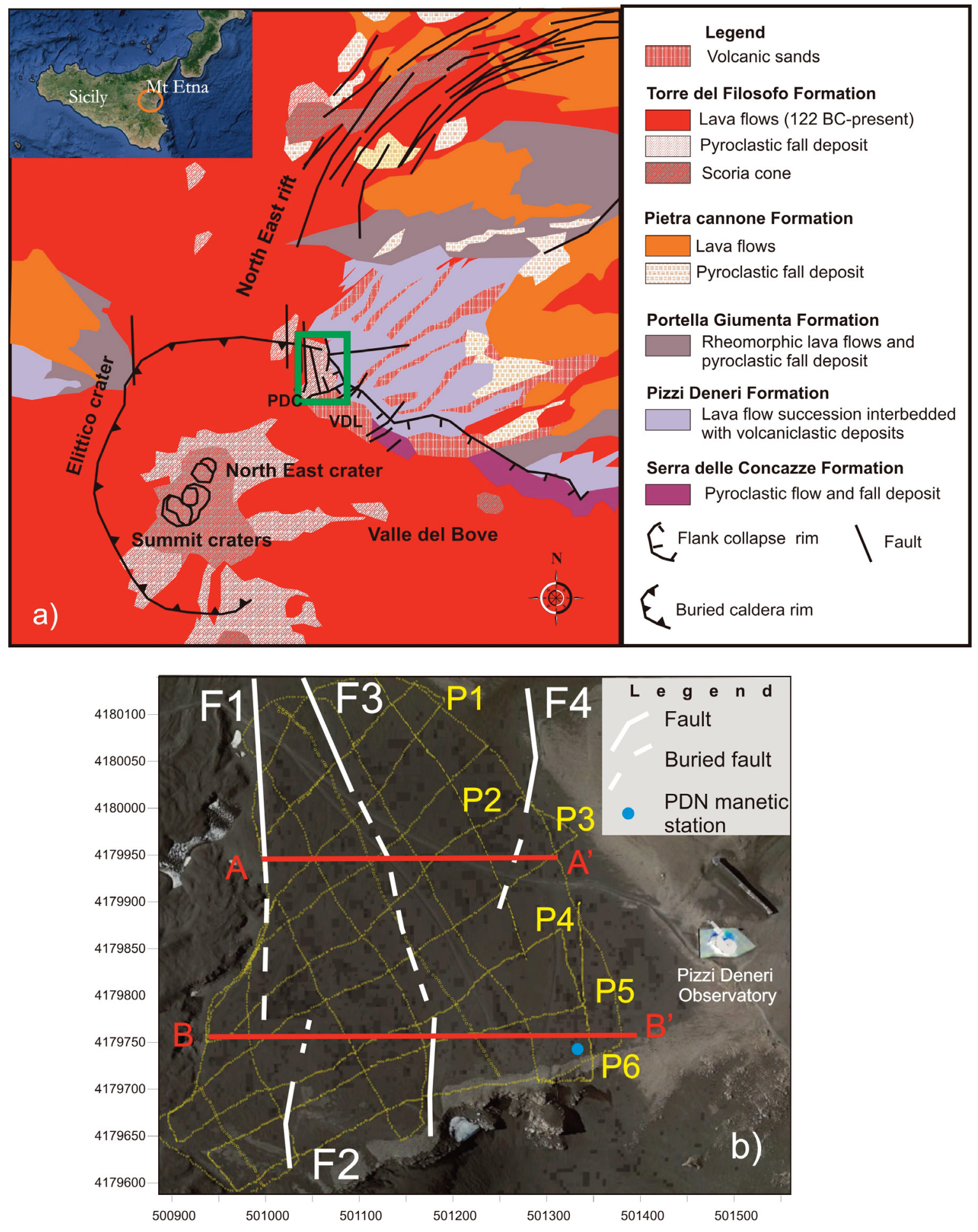

Figure 1. Simplified geological map (modified after Branca et al. [2011]) of Etna showing location of the investigated area (a); in the inset the main faults mapped by Azzaro et al. [2012] are reported, yellow lines indicate magnetic measurements and $\mathrm{AA}^{\prime}$ and $\mathrm{BB}$ ' represent the profile chosen for the modelling (b). 


\section{Rosalba Napoli et al.}

more recent volcanic activity [Branca et al., 2011]. This area is also affected by different North South-trending faults, that represent extension-accommodation features linked to the extensional tectonic regime of the NorthEst Rift [Azzaro et al., 2012]. To date no study has been carried out on these North South-trending faults, whose field evidence is sometimes obscured by accumulation of lava flows and volcaniclastic deposits, by strong erosion and by the collapsed rim of the VDL. No detailed information, is available about their characteristics (geometry, depth, etc.) nor the relationships between them have been entirely elucidated, therefore, it is not yet clear which role they could play during a magmatic intrusion, and in particular if they could be activated and became preferential ways for magma upraise in this area.

\section{Magnetic Survey}

A high resolution ground magnetic survey was carried out on PDC, over an area of about $0.2 \mathrm{~km}^{2}$. Magnetic data were acquired by a GSM19 Overhauser magnetometer with $0.01 \mathrm{nT}$ resolution. Simultaneously, GPS data were also collected by a Garmin's Etrex receiver to geo-reference magnetic measurements. More than 2,500 measurements were gathered with a sampling rate of $3 \mathrm{~s}$ corresponding to a sampling interval of about $3 \mathrm{~m}$ along a network of profiles describing an irregular grid crossing the main faults (F1, F2, F3 and F4) mapped in the PDC area by geological studies [Azzaro et al., 2012]. The magnetic sensor was positioned at a height of two meters above the ground surface to reduce noise. Data reduction process included removal of the diurnal variation of the magnetic field using data continuously recorded at the station PDN (Figure 1b) of the permanent network for magnetic monitoring of Mt. Etna [Del Negro et al., 2004; Napoli et al., 2008]. Magnetic survey was carried out during a quiet magnetic day, (the geomagnetic $\mathrm{K}$ index values is less than 2). This allowed for a sufficient removal of transient variations from external sources, so that a suitable accuracy could be achieved. The observed magnetic field was not reduced with respect to the normal field, IGRF, because of the limited extension of the area. For relatively small survey area, indeed, the removal of IGRF is not required because its wavelengths are larger with respect to the size of the survey [Kearey and Brooks, 1991]. To obtain the magnetic anomaly map, data were reduced to an equally spaced grid using the kriging method (kriging point type) with no drifts and a circular search ellipse. This is one of the more flexible and effective methods to produce an accurate grid of any type of data set, and unlike other methods such as the minimum curvature, it incorporates anisotropy and underlying trends in an efficient and natural manner and does not create high magnitude artifacts in areas of no data [Yang et al., 2004].

The magnetic anomaly grid (Figure 2) is characterized by two intense maxima striking South-North and EastWest, respectively aligned, that intersect with each other in the middle part of PDC. Other maxima are exposed along the VDL rim but they are not completely mapped since they are truncated by the caldera border.

In order to detect the possible anomalies ascribable to the faults affecting PDC area, six magnetic profiles (P1-P6) with East-West orientation, therefore perpendicularly crossing the F1, F2, F3 and F4 faults, were selected (Figure1b). The position of the fault traces was taken from the geological mapping survey [Azzaro et al., 2012]. Generally, in correspondence of the mapped fault zones, the magnetic anomalies show a clear sharp shortwavelength minima, with a range of amplitudes from few hundred to more than a thousand of $\mathrm{nT}$ in profile view (Figure 3). These large variations may be associated with the thickness of the volcanic deposits with different magnetic properties resulting in tectonic juxtaposition across fault zones. Although, no direct measurements of remanent magnetization (Jr) and susceptibility $(\chi)$ are available for volcanic rocks outcropping in this area (lava flows covered by several meters of more recent ash and volcaniclastic deposits) it is reasonable to hypothesize that the lava flows have higher Jr and $\chi$ values than those of the volcaniclastic products. Indeed, laboratory tests carried out on different samples of volcanic rocks, collected in different areas of the volcano, reveal that the average $\mathrm{Jr}$ and $\chi$ values of the Etnean lava flows are on average $7.5 \mathrm{~A} / \mathrm{m}$ and $3.5 \times 10^{-2} \mathrm{SI}$ respectively, while for volcaniclastic deposits the Jr values range between 2 and $3 \mathrm{~A} / \mathrm{m}$ and $\chi$ between $1 \times 10^{-2}$ and $2 \times 10^{-2}$ SI [Del Negro and Napoli, 2002; Nicolosi et al., 2014; Branca et al., 2019]. 


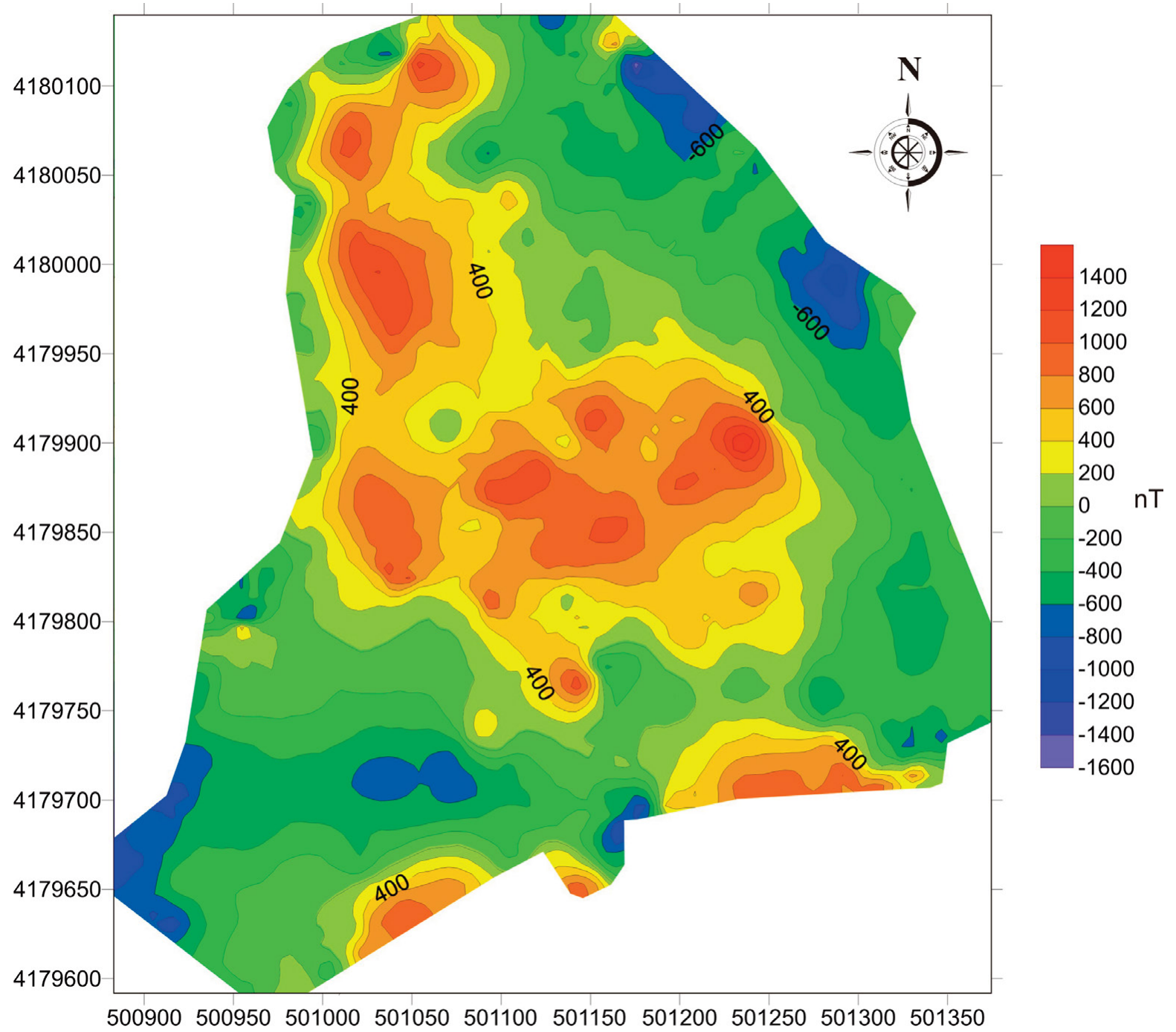

Figure 2. Total field magnetic anomaly grid of the Piano delle Concazze area.

\section{Filtering techniques}

The articulated distribution, morphology and arrangement of magnetic anomalies observed in the magnetic anomaly grid (Figure 2), reflects the superposition of multiple magnetic sources that can be related to the main shallow and deep geological structures of the investigated area.

In order to minimize the dipolar nature of the measured magnetic field, the reduction to the pole transformation (RTP) is used. In this way, the shape of the magnetic anomalies is more closely related to the geometry [Baranov, 1957] and the location of sources, particularly source edges, can more readily be determined. With this aim, we applied the RTP to the diurnally corrected data (Figure 4). To produce the RTP grid we used a magnetic inclination $53^{\circ} \mathrm{N}$ and a magnetic declination $3.4^{\circ} \mathrm{W}$, along the direction of the present-day Earth's magnetic field. On Mt. Etna, indeed, volcanic rocks [about 0.5 Ma; Gillot et al., 1994] were emplaced after the last field reversal [0.78 Ma; Lowrie and Kent, 2004] and remanent magnetization is generally much greater than induced magnetization [Königsberger ratio is > 1; see e.g. Tric et al., 1994; Branca et al., 2019]. 
Rosalba Napoli et al.
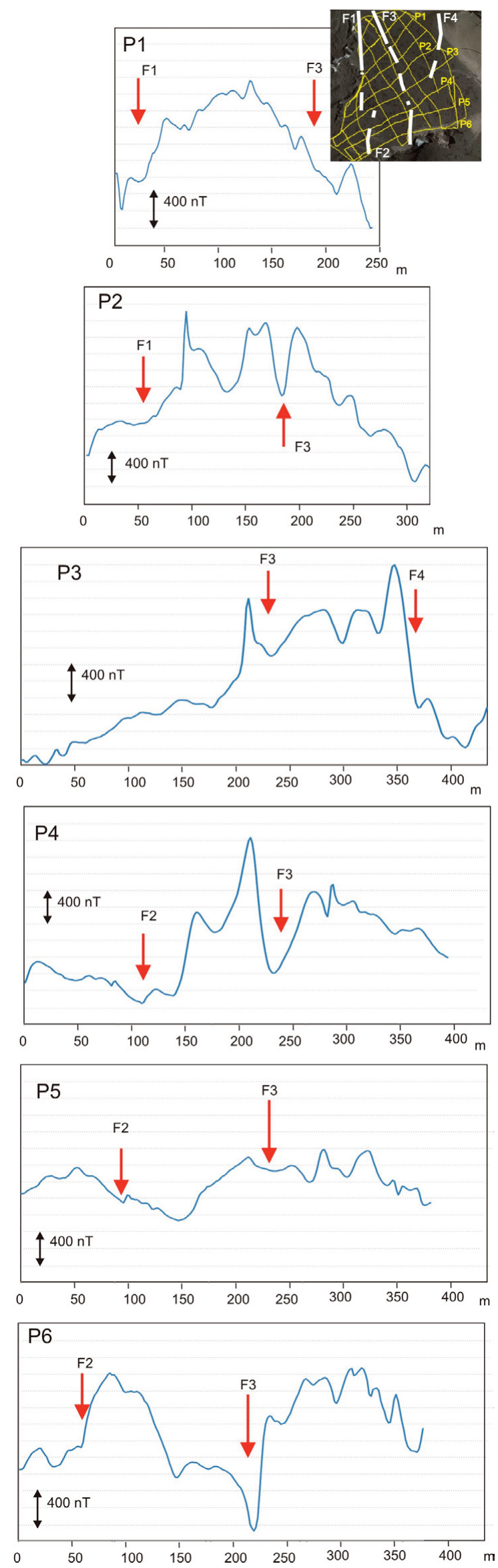

Figure 3. Total field magnetic anomalies observed in six profiles of general West-East orientation. Relative positions of profiles and the trends of fault zone mapped by Azzaro et al. [2012] are given in the inset. 
The maxima and minima, formerly described in the total intensity anomaly grid, are better defined in the RTP grid. In particular, the amplitude of the anomalies become larger and the two maxima that intersect each other, in the middle of the survey area, now appear well separated. Moreover, in the RTP grid, the eastern maximum observed along the caldera rim shows a South-North alignment that was not so evident in the total intensity anomaly grid.

To distinguish the near surface structures from the deeper ones and determine the magnetic source parameters, in particular locations of boundaries and depths, we applied different filtering techniques based on the derivatives of the magnetic data [Salem et al., 2008; Al-Garni 2010; Saada, 2015] through the Geosoft Oasis Moantaj Viewer software [Geosoft, 2018]. These techniques allow to separate the contribution of the different magnetic sources and hence, to better clarify their relationships.

In particular, to enhance the near surface structure, first vertical derivative, tilt angle derivative and Butterworth high-pass filter were used. Whereas, Butterworth low-pass filters were applied to bring out the deep-seated structure. Several tests were done before to select the more suitable filter parameters. Finally, the 3D Euler deconvolution has been used to estimate the depth and the structure indices of the causative sources. The structural index (SI), that is based on the concept of Euler homogeneity, is widely used in potential-field depth estimation because it evidences the geometrical nature of the source, and allow the separation of the depth and geometrical contributions to the observed field. For simple sources SI is a constant integer and is identical to the index of a simple power-law field fall-off with distance [Reid and Thurston, 2014].

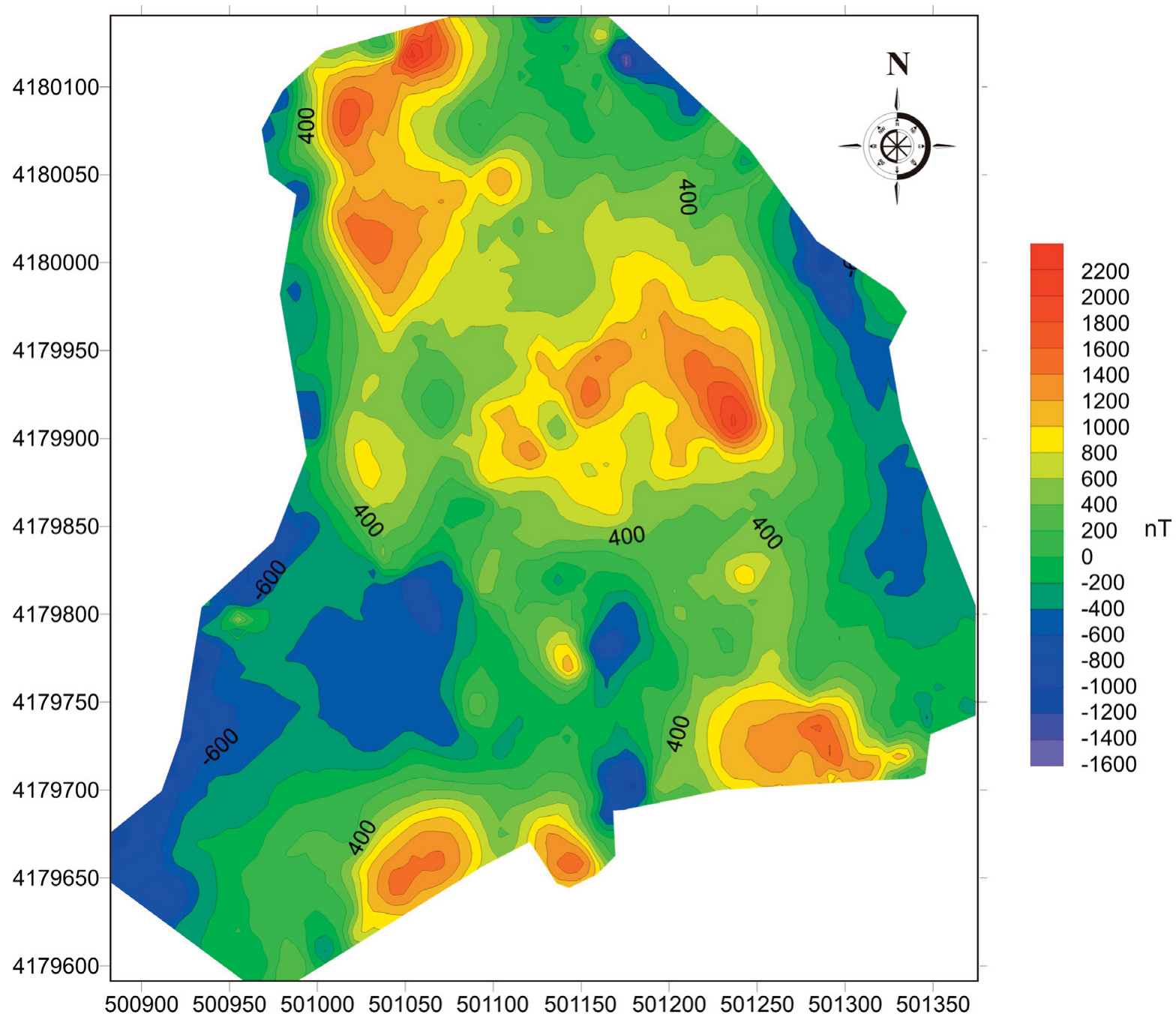

Figure 4. Grid of the reduced to the pole magnetic data. 


\section{Rosalba Napoli et al.}

\subsection{First Vertical derivative}

The first vertical derivative (VDR) computes the change in the vertical direction of the magnetic field [Blakely, 1995]. This method, using a Fast Fourier Transform, effectively highlights the high frequency component of the magnetic field, caused by the local shallowest geological sources and by the top parts of deep bodies, and suppresses the low frequency content due to the deeper sources [Paine, 1986]. The VDR emphasizes higher gradient, provides sharper resolution and approximates shape outlines of the near surface magnetic anomalies. In particular, anomaly peaks locate the centers of sources, while the zero contour lines indicate their boundaries. Considering that the VDR is potentially less sensitive to noise in the data than higher order derivatives, these last have been disregarded and only the VDR was calculated for the magnetic RTP data of the PDC area (Figure 5a).
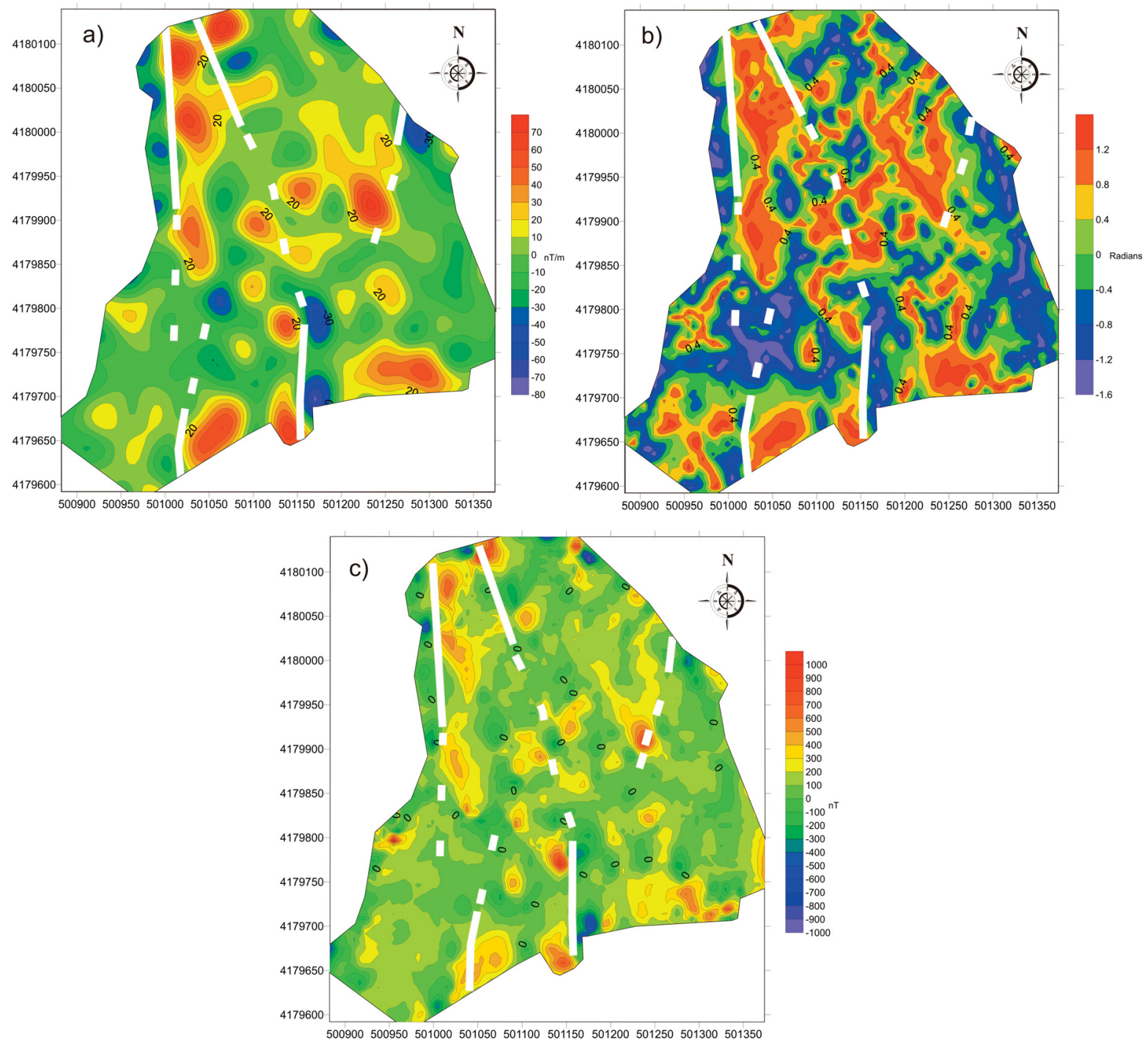

Figure 5. Grid of the first vertical derivative (1VDR) magnetic data (a); grid of the tilt angle derivative (b); grid of the Butterworth high-pass wavenumber filtered magnetic data (c). The main faults mapped by Azzaro et al. [2012] are also reported (continuous white lines represent exposed faults and dashed lines the buried ones). 


\subsection{Tilt angle derivative}

The tilt derivative (TDR) method, which is generally used for enhancing features and causative body edge detection in magnetic anomaly grid [Miller and Singh, 1994], was also applied (Figure 5b). The TDR, contrasting other commonly used derivatives, that show an amplitude response closely linked to the amplitude of the total magnetic intensity anomaly, is independent of amplitude of the TMI anomaly, but is controlled by the reciprocal of the depths of the sources [Verduzco et al., 2004]. The TDR is defined as:

$$
T D R=\tan ^{-1}\left(\frac{V D R}{T H D R}\right)
$$

where VDR and THDR are the first vertical and total horizontal derivative of the magnetic field, respectively. Because of the nature of the arctan trigonometric function, all amplitudes range between $+90^{\circ}$ and $-90^{\circ}\left(+\frac{\pi}{2}\right.$ and $\left.-\frac{\pi}{2}\right)$ nevertheless the amplitude of VDR and THDR [Verdzuco et al., 2004].

This method attempts to equalize the signals amplitudes across the survey area, where the peaks of the transformed data are positioned directly over the magnetic body's centers and the zero, crossing the anomalies, is over or close to the magnetic source edges. In this way, the TDR is a useful tool to trace the outline of the magnetic edges.

\subsection{Butterworth filters}

The Butterworth filter was applied in the frequency domain. It allowed for applying straightforward high-pass and low-pass filters to data because we could easily control the degree of filter roll-off while leaving the central wave number fixed.

The Butterworth high pass filter (BWHP) was used to enhance the shorter wavelength component of the near surface anomalies and attenuate the longer wavelength component. In the investigated area a BWHP filter of rolloff order "8" and wavelengths $<300 \mathrm{~m}$ was applied to pass the shallower anomalies (Figure 5c).

On the other hand, in order to reveal deep-seated causative structures, Butterworth low pass filter (BWLP) was applied. It allowed to attenuate the shorter wavelength of the near surface anomalies and highlight the longer wavelength caused by deeper causative sources. We used a BWLP filter with the same roll-off order " 8 " but with wavelengths $>500 \mathrm{~m}$ (Figure 6). The BWLP reveals anomalies with semi-circular and elongated shapes with a SouthNorth alignment.

\subsection{D Euler deconvolution}

The 3D Euler deconvolution has been applied to estimate the depth and the structural index of the causative bodies [Reid et al., 1990; Silva and Barbosa, 2003; Dewangan et al., 2007]. A window size of $100 \mathrm{x} 100 \mathrm{~m}$ was used. The depth was calculated for various structural indices (SI) of 0, 1 and 2 (Figure 7), which describes the rate of falloff of the magnetic field and is related to the shape of the source bodies. Solutions obtained from the most appropriate structural index for a fault are normally recognized by how well they cluster in a line. Solutions were rejected if their errors in the least-squares inversion were greater than $10 \%$ of the depth.

\section{Forward Modeling}

To put constraints on the geometry (dimension and depth) of the sources responsible for the main magnetic anomalies of the PDC area, a forward modeling approach was used by means of the interactive software Potent v3.06. 2.5D modeling was carried out along two East-West profiles, (AA' and BB') selected taking into account the main anomalies displayed on the magnetic anomaly grid and crossing the main faults. The anomalies were modelled by polygonal prismatic bodies with different magnetic properties. The magnetization and susceptibility of each body, were set taking advantage of Jr and $\chi$ values reported in literature [Del Negro and Napoli, 2002; Nicolosi et al., 2014; 


\section{Rosalba Napoli et al.}

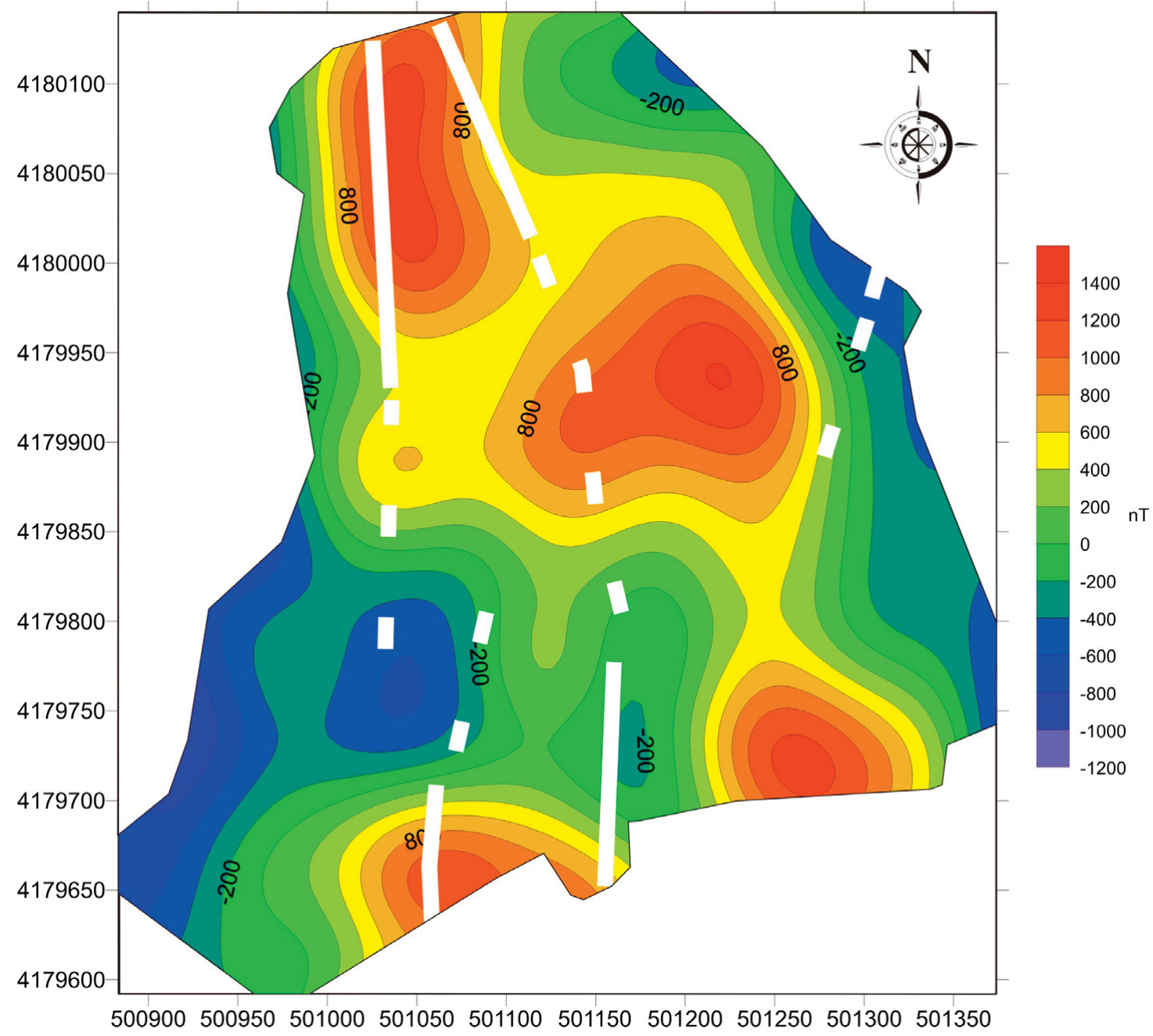

Figure 6. Grid of the Butterworth low-pass wavenumber filtered magnetic data. The main faults mapped by Azzaro et al. [2012] are also reported (continuous white lines represent exposed faults and dashed lines the buried ones).

Branca et al., 2019] for petrographycally similar rocks. Therefore, we have assigned Jr and $\chi$ values ranging from 1 to $7.5 \mathrm{Am}^{-1}$ and from 0.01 to 0.035 S.I. to the volcaniclastic deposits and to volcanic rocks, respectively. The initial models were constrained by available surface geology data and successively they were adjusted through a "trial and error" approach until a satisfactory fit was achieved. In particular, we varied the magnetic properties and the boundaries between bodies until the RMS error between the observed and calculated anomaly is about 20 nT for each profile. The investigated area is entirely covered by incoherent volcanic material produced by the recent explosive volcanic activity, this deposit was modelled in both profiles as the volcaniclastic deposit V1 with $\mathrm{Jr}=1$ $\mathrm{Am}^{-1}$ and $\chi=0.01$ S.I. (Figure 8 ). Below this coverage, characterized by a mean thickness of few meters, different volcanic bodies are modelled. A single body, A1, with $\mathrm{Jr}=4.5 \mathrm{Am}^{-1}$ and $\chi=0.03$ S.I. is revealed in the western edge of the profile $\mathrm{AA}^{\prime}$. On the basis of its magnetic properties and its location, it could be reasonably associated to the lava flows outcropping in the western edge of the investigated area. A1 is in contact, by a steep scarp, ascribable to the F1 fault, with the volcaniclastic coverage V1, whose thickness increases in this area, and with the body A2 whose magnetic properties ( $\mathrm{Jr}=2.5 \mathrm{Am}^{-1}$ and $\chi=0.02$ S.I.) are intermediate between $\mathrm{A} 1$ and $\mathrm{V} 1$. The more intense EastWest anomaly located in the middle of the profile is well modelled as a single body, A3, characterized by higher magnetization values ( $\mathrm{Jr}=7.5 \mathrm{Am}^{-1}$ and $\chi=0.035$ S.I.). It stretches, along the West-East direction for more than 200 $\mathrm{m}$ with a mean thickness of about $40 \mathrm{~m}$, that abrupt decreases eastwards due to the F4 fault, while at west is bounded by a buried steep scarp that spatially correspond to the F3 fault reported by Azzaro et al. [2012]. 

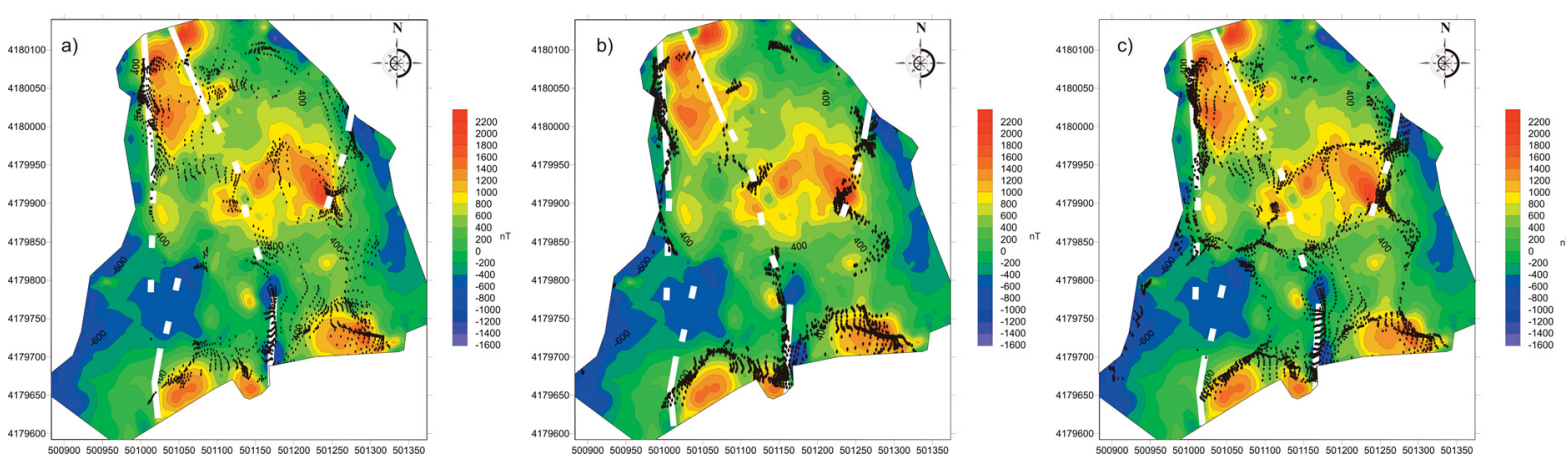

Figure 7. Euler solution results, (a) structural index $=0$, (b) structural index $=1$, (c) structural index $=2$. The main faults mapped by Azzaro et al. [2012] are also reported (continuous white lines represent exposed faults and dashed lines the buried ones).

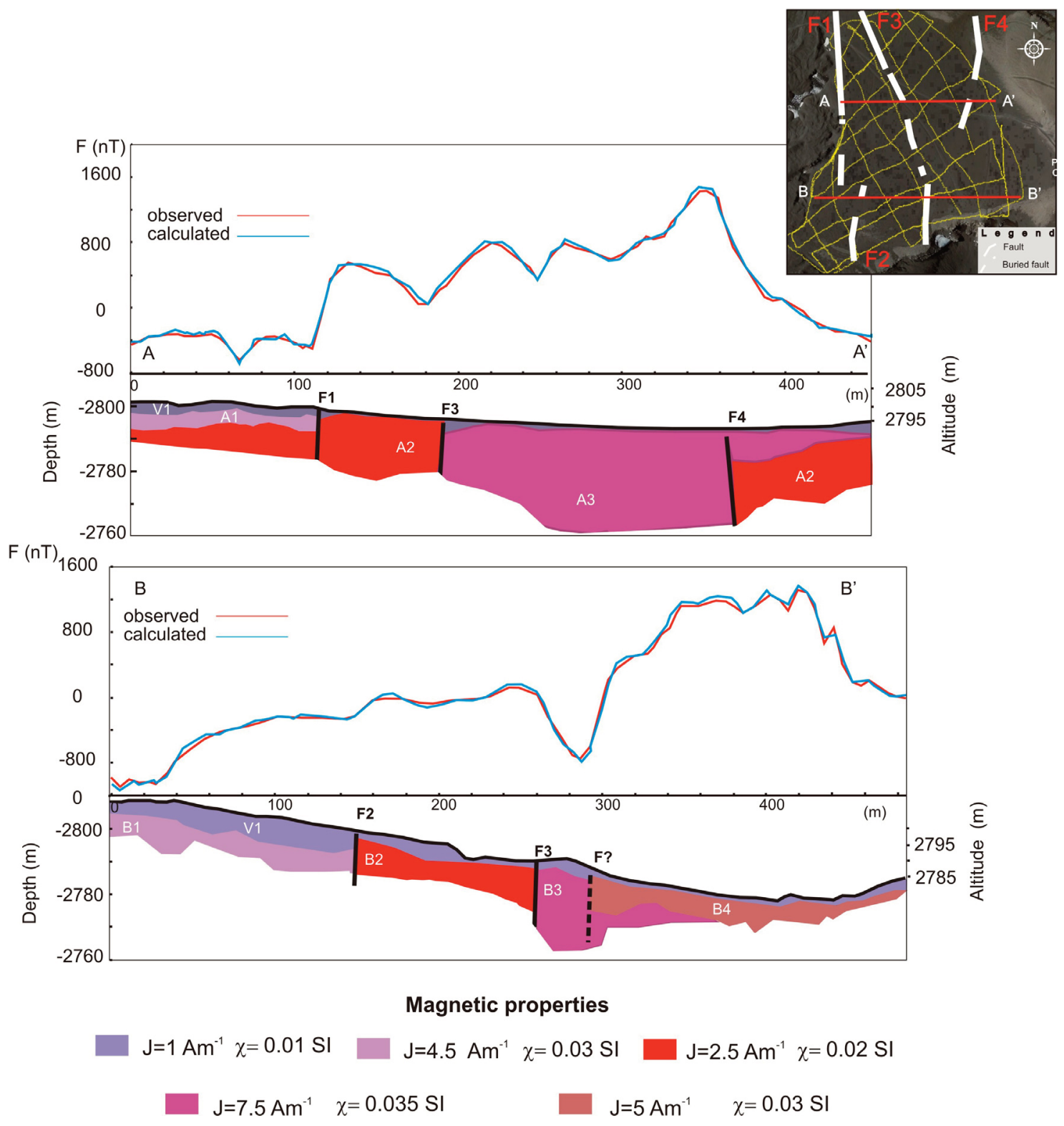

Figure 8. 2.5D modeling along profile $\mathrm{AA}^{\prime}$ and $\mathrm{BB}^{\prime}$. The location of the profiles are shown in the inset. 


\section{Rosalba Napoli et al.}

The high magnetization values of A3, in literature are generally associated to lava flows and/or massive intrusions. There is no additional information to be able to discern between lava flows and intrusion, but considering the proximity of A3 to the lava flow succession of the Pizzi Deneri formation, that is related to the Ellittico activity [Coltelli et al., 1994; Branca et al. 2011], we reasonable assume that it is ascribable to this volcanic unit.

Southwards, a second profile (BB') was also selected and modelled. Along BB' profile the thickness of V1 increases up to about $10 \mathrm{~m}$, covering, in the western area, the single body B1 with the same magnetization and susceptibility values ( $\mathrm{Jr}=7.5 \mathrm{Am}^{-1} \chi=0.035$ S.I.) of A1. B1 is bounded by F2 fault and laterally is in contact with B2 whose magnetic properties are similar to A2. Eastwards B2 is replaced by the high magnetized body B3 $\left(\mathrm{Jr}=7.5 \mathrm{Am}^{-1}\right.$ and $\chi=0.035$ S.I.) that is well bounded by two sharp scarps. The scarp between B2 and B3 is ascribable to the southern edge of the F3 fault, while there is no indication in literature about the presence of another fault that could be ascribable to the scarp between $\mathrm{B} 3$ and the volcanic body, $\mathrm{B} 4\left(\mathrm{Jr}=5 \mathrm{Am}^{-1}\right.$ and $\chi=0.03$ S.I.).

The bodies A1, A2, and A3, modelled along the AA' profile have the same magnetic properties (Table 1) of the bodies, B1, B2 and B3, detected along the BB' profile, considering the closeness between the two profiles, we reasonable suppose that they are associated to the same volcanic units. It is worth noting that the estimation of vertical extent of faults is interred by the lack of data on rock magnetic property at depth and to a simplified polygonal model [Lopez-Loera et al. 2010]. The obtained geological outline is in agreement with previous geological studies that revealed in PDC area a lava flow succession interbedded with volcaniclastic products related to the activities of the Ellittico volcano.

\begin{tabular}{ccc} 
Body & Remanent magnetization (Jr) & Susceptibility $(\chi)$ \\
V1 & $1.0 \mathrm{Am}^{-1}$ & $0.010 \mathrm{SI}$ \\
\hline A1 & $4.5 \mathrm{Am}^{-1}$ & $0.030 \mathrm{SI}$ \\
\hline A2 & $2.5 \mathrm{Am}^{-1}$ & $0.020 \mathrm{SI}$ \\
\hline A3 & $7.5 \mathrm{Am}^{-1}$ & $0.035 \mathrm{SI}$ \\
\hline B1 & $4.5 \mathrm{Am}^{-1}$ & $0.030 \mathrm{SI}$ \\
\hline B2 & $2.5 \mathrm{Am}^{-1}$ & $0.020 \mathrm{SI}$ \\
\hline B3 & $7.5 \mathrm{Am}^{-1}$ & $0.035 \mathrm{SI}$ \\
\hline B4 & $5.0 \mathrm{Am}^{-1}$ & $0.030 \mathrm{SI}$ \\
\hline
\end{tabular}

Table 1. Magnetic properties of the bodies modelled along the AA' and BB' profiles shown in Figure 8.

\section{Discussion and conclusions}

The study area is characterized by clear defined anomalies with short wavelengths, sharp amplitude and round to stretched oval shape. Nevertheless, the pattern, location and clear isolation of the individual shallow magnetic sources, depicting the near surface structure, cannot be delineated efficiently without the application of different filtering techniques and forward modeling. The combination of the first vertical derivative (VDR), tilt angle derivative (TDR) and Butterworth filters, allowed us to detect and describe the main geo-structural features of the study area, while the Euler deconvolution and forward modeling constrained their depth and geometry. The obtained results were compared and integrated with the available geological information [Azzaro et al., 2012] to be interpreted with a better confidence. The results reveal that some of the high frequency components are due to the South-North subsurface structural features with surface exposure, while the large wavelength components are related to larger structures (see A3 in the profile AA') that are not reported in the available geological maps. 
A strong correlation between the South-North fault systems affecting this area and the outline of the high frequency and short wavelength components was effectively enhanced by the VDR (Figure 5a). Indeed, the zero crossing of the first vertical derivative well delineates the F1 fault (Figure 1). In particular, it reveals a NorthSouth aligned magnetic anomaly, from the northern edge of the magnetic measurements grid, that spreads for about $200 \mathrm{~m}$ to the south and is perfectly coincident with the trace mapped in the geological map. A good correspondence is also obtained for the F4 and F2 faults. This last, is reported in the available geological map as an exposed fault 100 meters long, while in the VDR grid seems to be longer than expected, extending for about 300 meters to the north, parallel to the F1 fault direction (Figure 5a). These results well fit with the schematic geological outline obtained by forward models performed along the profiles AA' and BB'. On the other hand, a significant discrepancy concerns the F3 fault, that is mapped in previous geological study [Azzaro et al., 2012] as a $300 \mathrm{~m}$ long structure composed by exposed and buried segments, crossing from North to South the whole investigated area. The forward model revealed a buried segment of F3 fault along the profile AA', while no significant evidence was found by filtering techniques in the same area. Only in proximity of the VDL, where the F3 fault southern tip outcrops for about $100 \mathrm{~m}$, a South-North elongated magnetic anomaly is evident and overlaps with it in the VDR grid, but it seems that it does not develop further.

Similar results are obtained both by TDR technique and by high-pass Butterworth filters, however in these last cases the anomalies separation is not so enhanced as in the VDR and anomalies appear less sharp (Figures $5 \mathrm{~b}, 5 \mathrm{~d})$. In this study, therefore, the VDR seems to perform an effective signal detection better than the other applied filtering techniques.

Wider anomalies with longer wavelength were instead depicted by the Butterworth low-pass filter (BWLP). An intensely magnetized volume, roughly East-West elongated, was revealed in the central part of the investigated area, that is in agreement with the massive lava flow modelled along the AA' profile and associated to the Ellittico activity. Two well isolated magnetic anomalies are also evident in correspondence to the exposed rim of the VDL caldera, and even if they appear truncated and are not completely defined they can be reasonably related both to the morphological effect of the caldera depression and to the volcanic body buried (Figures 6 and 8) and outcropping in this area. Moreover, an elongated South-North trend is observed in spatial correspondence of F1 fault, in the northern part of PDC area. It could be related to the regional trend which controls the subsurface structures beneath the study area, but due to the small extent of our survey no detailed information can be obtained from our measurements on the deeper structures. An enlargement of the survey area, that would help to fill this gap, is prevented by the proximity of the VDL depression to the south and the steepness of the areas surrounding PDC to the east and west.

Predominant significant distribution and dense clustering of the solutions obtained by 3D Euler convolution were recognized along the rims of the main anomalies, in particular in correspondence of the F1, the southern tip of F3 and F4 faults. After various trials, the suitable structural index seems to be 1 which gives the tightest clustering of solutions. This structural index (SI) may be best associated to an idealized normal fault, with a single magnetic contrast at a fault plane that has finite depth extent [Reid, 2003]. Approximately 3000 estimates of source location are plotted on top of the magnetic anomaly (Figure 7) and the depth values are color coded (Figure 9) for solutions related to SI of 1 . The corresponding depth estimations were ranging from less than 10 $\mathrm{m}$ to $40 \mathrm{~m}$ reflecting that the faults are very shallow seated. These findings well support and strengthen the results obtained by the forward modeling, where the faults do not extend at depths greater than $30 \mathrm{~m}$. The pattern, trend and location of the depicted shallow and deep structures are well consistent with the local tectonics described by Azzaro et al. [2012] where the North South-trending faults in the PDC area are the response of the, extension-accommodation action produced by the opening of the North-East rift.

Our findings can be used in aiding volcanic hazard assessments in this area, providing new constraints to better characterize the fault systems and defining with more details their spatial distribution. The presence of high magnetized volume detected at depth in the central part of the study area, ascribable to massive lava flows, testifies that this area has been already invaded by magma. However, the North-South trending faults don't seem to be deep rooted, as they affect the superficial layers up to a maximum depth of about $40 \mathrm{~m}$. This would rule out the possibility that they can be activated during a magma intrusion process or that they could become a preferential way for magma ascent from depth. Careful definition of in situ properties of rocks and an enlargement of the survey area by aeromagnetic measurements could help to improve the understanding of the fault systems of PDC area at deeper levels and consequently to support our results. 


\section{Rosalba Napoli et al.}

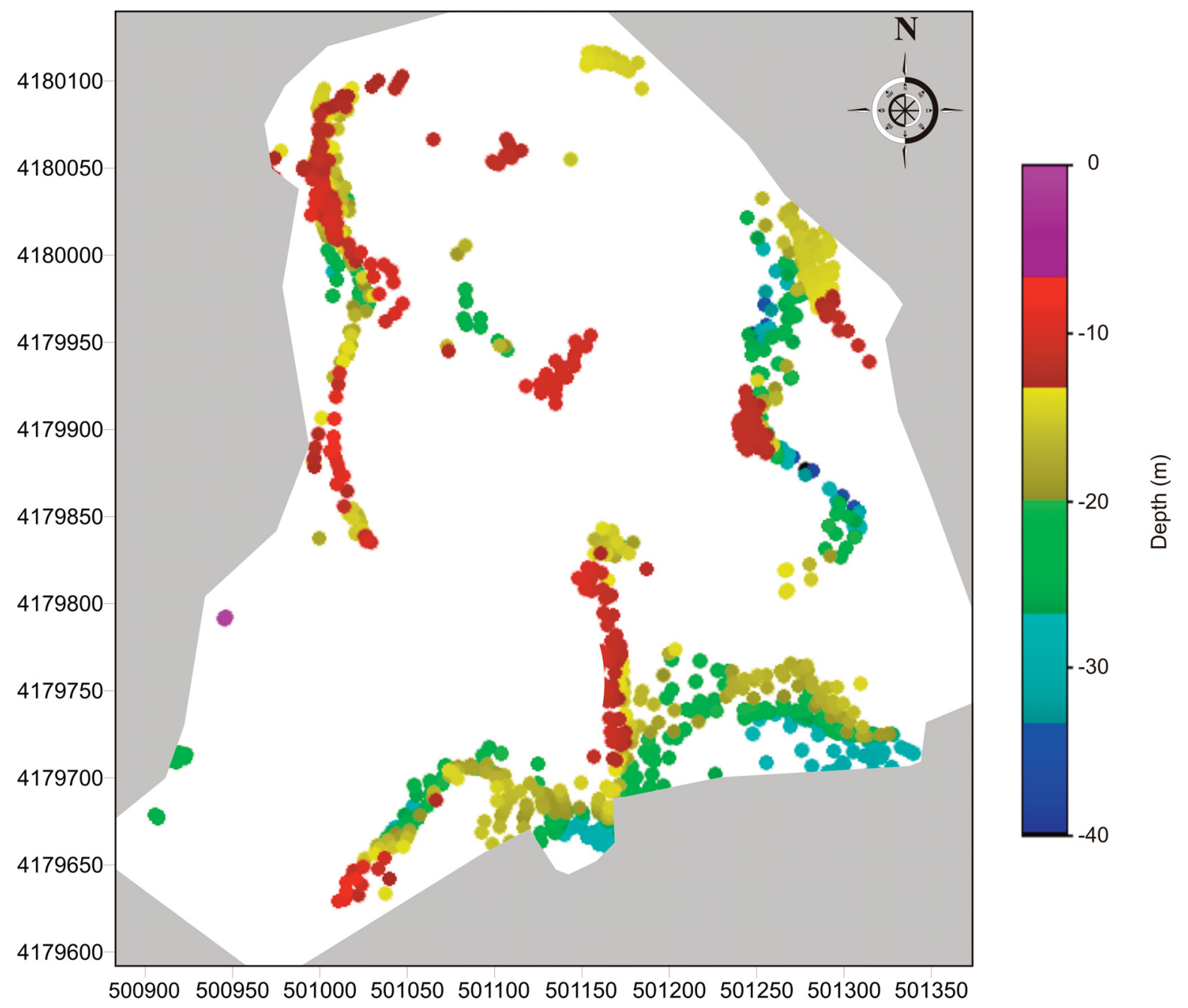

Figure 9. Euler deconvolution applied to the total magnetic intensity calculated for SI $=1$.

Acknowledgments. We thank the Editor Paola De Michelis and two anonymous reviewers for their helpful comments.

\section{References}

Al-Garni M.A., (2010). Magnetic survey for delineating subsurface structures and estimating magnetic sources depth, Wadi Fatima, KSA. J. King Saud University, Science, 22, 87-96.

Andronico D. and L. Lodato (2005). Effusive Activity at Mount Etna Volcano (Italy) During the 20th Century: A Contribution to Volcanic Hazard Assessment, Nat. Hazards, 36, 407-443.

Azzaro R., S. Branca, K. Gwinner, M. Coltelli (2012). The volcano-tectonic map of Etna volcano, 1:100.000 scale: an integrated approach based on a morphotectonic analysis from high-resolution DEM constrained by geologic, active faulting and seismotectonic data, Ital. J. Geosci. (Boll.Soc.Geol.It.), 131, 1, 153-170, doi:10.3301/IJG.2011.29.

Barberi F., A. Gandino, A. Gioncada, P. La Torre, A. Sbrana, C. Zenucchini (1994). The deep structure of the Eolian arc (Filicudi-Panarea- Vulcano sector) in light of gravity, magnetic and volcanological data, J. Volcanol. Geotherm. Res., 61, 189-206.

Blaikie T.N., L. Ailleres, P.G. Betts, R.A.F. Cas, (2014). Interpreting subsurface volcanic structures using geologically constrained 3-D gravity inversions: examples of maardiatremes, Newer Volcanics Province, southeastern 
Australia, J. Geophys. Res.: Solid Earth, 119, 3857-3878, http://dx.doi.org/10.1002/2013JB010751.

Blakely R.J. (1995). Potential theory in gravity and magnetic applications, Cambridge University Press, Cambridge

Blanco-Montenegro I., J.M. Torta, A. Garcia, V. Araña (2003). Analysis and modelling of the aeromagnetic anomalies of Gran Canaria (Canary Islands), Earth Planet. Sci. Lett., 206, 601-616.

Branca S. and P. Del Carlo (2005). Types of eruptions of Etna Volcano AD 1670-2003: Implications for short-term eruptive behavior, Bull. Volcanol., 67, 732-742.

Branca S., M. Coltelli, G. Groppelli and F. Lentini (2011). Geological map of Etna volcano, 1:50,000 scale, Italian J. Geosci., 130, (3), 265-291, https://doi.org/10.3301/IJG.2011.15.

Branca S., F. D’Ajello Caracciolo, A.B. Malaguti and F. Speranza (2019). Constraining age and volume of lava flow invasions of the Alcantara valley, Etna volcano (Italy). New insights from paleomagnetic dating and 3D magnetic modeling, J. Volcanol. Geotherm. Res., 374, 13-25.

Caratori Tontini F. (2016). Interpretation of gravity and magnetic anomalies at Lake Rotomahana: Geological and hydrothermal implications, J. Volcanol. Geotherm. Res., 314. 84-94.

Coltelli M., V.H. Garduno, M. Neri, G. Pasquarè and M. Pompilio (1994). Geology of the northern wall of the Valle del Bove, Mt. Etna (Sicily), Acta Vulcanol., 5, 55-68.

Del Negro C., R. Napoli (2002). Ground and marine magnetic surveys of the lower eastern flank of Etna volcano (Italy). J. Volcanol. Geotherm. Res., 114, 357-372.

Del Negro, C., G. Currenti., R. Napoli and A. Vicari (2004). Volcanomagnetic changes accompanying the onset of the 2002-2003. Eruption of Mt. Etna (Italy), Earth Planet. Sci. Lett., 229, 1-14.

Demirel S., B. Alpar, C. Yaltırak, D. Vardar and H. Kurt (2020). Northern segment of the North Anatolian Fault in the Gulf of Izmit inferred from marine magnetic anomalies, Mar. Geophys. Res., 41, 6 (2020), https://doi.org/10.1007/s11001-020-09399-6

Dewangan P., T. Ramprasad, M.V. Ramana, M. Desa, B. Shailaja (2007). Automatic interpretation of magnetic data using Euler deconvolution with nonlinear background, Pure appl. Geophys., 164, 2359-2372.

Dobrin M.B., (1960). Introduction to Geophysical Prospecting, McGraw-Hill Book Company, New York, 445.

Finn C.A., L.A. Morgan (2002). High-resolution aeromagnetic mapping of volcanic terrain, Yellowstone National Park, J. Volcanol. Geotherm. Res., 115 (1-2), 207-231.

Geosoft Oasis Montaj Viewer (2018). Version 9.4.4 for the Earth Science, Geosoft Inc, Toronto, Canada.

Gillot P.Y., G. Kieffer, R. Romano (1994). The evolution of Mount Etna in the light of potassium-argon dating, Acta Vulcanol. 5, 81-87.

Grauch V.J.S., M.R. Hudson and S.A. Minor (2001). Aeromagnetic expression of faults that offset basin fill, Albuquerque basin, New Mexico, Geophysics, 66, 707-720.

Hudson M.R., V.J.S. Grauch, S.A. Minor, J.S. Caine and A.M. Hudson (2001). Rock magnetic properties, magnetic anomalies, and intrabasin faulting: Santa Fe Group basin fill, Rio Grande rift, New Mexico, EOS, Transactions, American Geophysical Union, 82, 338-339.

Lowrie W., D.V. Kent (2004). Geomagnetic polarity timescales and reversal frequency regimes, In: Channell J.E.T., D.V. Kent, W. Lowrie, J. Meert, (eds). Timescales of the Palaeomagnetic Field, America Geophysical Union., 117-129.

Miller H. G. and V. Singh (1994). Potential field tilt - A new concept for location of potential field sources, J. Applied Geophys., 32, 213-217.

Monaco C., G. De Guidi and C. Ferlito (2010). The morphotectonic map of Mt. Etna, Ital. J. Geosci., 129, 3, 408-428, doi:10.3301/IJG.2010.11.

Napoli R., G. Currenti and C. Del Negro (2007). Internal structure of Ustica volcanic complex (Italy) based on a 3D inversion of magnetic data, Bull. Volcanol., doi:10.1007/s00445-007-0115-8.

Napoli R., G. Currenti, C. Del Negro, F. Greco and D. Scandura, (2008). Volcanomagnetic evidence of the magmatic intrusion on 13th May 2008 Etna eruption, Geophys. Res. Lett., 35, L22301, doi:10.1029/2008GL035350.

Napoli R. and G. Currenti (2016). Reconstructing the Vulcano Island evolution from 3D modeling of magnetic signatures, J. Volcanol. Geotherm. Res., 320, 40-49, doi:10.1016/j.jvolgeores.2016.04.011.

Nicolosi I., F. D’Ajello Caracciolo, S. Branca, G. Ventura and M. Chiappini (2014). Volcanic conduit migration over a basement landslide at Mount Etna (Italy), Sci. Rep., 4, 5293; doi: 10.1038/srep05293.

Paine J.W. (1986). A comparison of methods for approximating the vertical gradient of one- dimensional magnetic field data, Geophysics, 51 (9), 1725-1735. 


\section{Rosalba Napoli et al.}

Reid A.B., Allsop, J.M., Granser, H., Millett, A.J., and Somerton, I.W. (1990). Magnetic interpretation in three dimensions using Euler deconvolution: Geophysics, 55, 80-91.

Reid A.B. (2003). Euler magnetic structural index of a thin-bed fault, Geophysics, 68, 1255-1256.

Reid A.B and J. Thurston (2014). The structural index in gravity and magnetic interpretation: Errors, uses, and abuses, Geophysics, 79, 4, J61-J66, doi:10.1190/geo2013-0235.1.

Salem A., S. Williams, D. Fairhead, R. Smith and D. Rava (2008). Interpretation of magnetic data using tilt-angle derivatives, Geophysics, 73, 1, L1-L10, doi:10.1190/1.2799992.

Saada A.S. (2015). Edge Detection and Depth Estimation from Magnetic Data of Wadi Araba, Eastern Desert- Egypt, IOSR, J. Applied Geol. Geophys., 3, 6, I, 33-45.

Schrott L., and O. Sass (2008). Application of field geophysics in geomorphology: Advances and limitations exemplified by case studies, Geomorphology, 3, 1-2, 55-73.

Silva J.B.C. and V.C.F. Barbosa (2003). 3D Euler deconvolution: Theoretical basis for automatically selecting good solutions, Geophys. Prosp., 45, 207-246.

Tric E., J.P. Valet, P.Y. Gillot, I. Lemeur (1994). Absolute paleointensities between 60 and 160 kyear BP from Mount Etna (Sicily), Phys. Earth Planet. Inter., 85, 113-129.

Yan J., Z. Wang, J. Wang and J. Song (2018). Using marine magnetic survey data to identify a gold ore-controlling fault: a case study in Sanshandao fault, eastern China, J. Geophys. Eng., 15, (3) 729-738, doi.org/10.1088/17422140/aa9c69.

Yang C-S., S-P. Kao, F-B. Lee, P-S. Hung (2004). Twelve different interpolation methods: a case study of Surfer 8.0, In: Paper presented at the Proceedings of the XXth ISPRS congress.

Verduzco B, J.D. Fairhead, C.M. Green and C. MacKenzie, (2004). New insights into magnetic derivatives for structural mapping, The Leading Edge, 23, 116-119. 